P. Pelosi

A. Aliverti

R. Dellacà

\title{
Chest wall mechanics in normal subjects and in critically ill patients
}

Die Mechanik der Brustwand bei normalen Personen und bei Patienten in kritischem Zustand

Zusammenfassung Veränderte mechanische Eigenschaften der Brustwand können verschiedene Aspekte der Atmungsfunktion wie Ventilation, Atmungsarbeit, Atmungsmuskulatur und Gasaustausch beeinflussen. Bis jetzt wurden verschiedene Methoden, inklusive schneller Atemwegsokklusion und der forcierten Oscillationstechnik angewendet, um die statischen und dynamischen Eigenschaften der Brustwand zu untersuchen. Die Rolle der Brustwand während der passiven und aktiven Ventilation wurde wegen der Schwierigkeiten der kompartimentalen Analyse noch nicht weitergehend untersucht.

Verschiedene Zustände, wie z.B. Anaesthesie und Lähmung, akute

Received: 18 January 1999

Accepted: 25 February 1999

Diese Arbeit basiert auf einem Beitrag im Yearbook of Intensive Care and Emergency Medicine 1998, edited by J.-L. Vincent, Springer-Verlag 1998

Dr. P. Pelosi $(\bowtie)$

Istituto di Anestesia e Rianimazione

Ospedale Policlinico

IRCCS

via F. Sforza 35, I-20122 Milano

A. Aliverti · R. Dellacà

Centro di Bioingegneria

Fondazione Don Gnocchi

IRCCS

Politecnico di Milano
Atemnotsyndrome (ARDS), chronisch obstruktive Lungenerkrankung (COPD), Kyphoskoliose und extremes Übergewicht zeigen eine enge Interaktion zwischen der Lunge und der Brustwand.

Bei ARDS-Patienten und COPDPatienten ist nicht nur die Mechanik der Lunge und der Atemwege abnormal, sondern auch die Brustwand kann verändert sein. Im Gegensatz dazu sind die Abnormitäten in der Brustwand bei Kyphoskoliose und extremem Übergewicht Zeichen einer Beeinträchtigung der Lunge.

In dieser Studie wird ein Modell der Brustwandmechanik bei normalen Personen dargestellt. Die Anwendung dieses Modells, welche auf eine Messung des Drucks und der Volumenverlagerung der verschiedenen Kompartimente basiert, wird durch eine neue optoelektronische Technik möglich, indem die Brustwand in ihren verschiedenen Komponenten - pulmonaler Brustkorb, abdominaler Rippenkorb und Abdomen - aufgegliedert wird.

Schlüsselwörter Brustwand - Normalpersonen - kritisch kranke Patienten

Summary Altered mechanical properties of the chest wall may influence different aspects of respiratory function, such as ventilation, work of breathing, respiratory muscles, and gas exchange. Up to now, different methods have been used to study the static and dynamical properties of the chest wall, including the rapid airway occlusion and the forced oscillation technique, but the role of the chest wall during passive and active ventilation has not been widely investigated due to the difficulties of compartmental analysis.

Different physiopathological conditions, such as anaesthesia and paralysis, acute respiratory distress syndrome (ARDS), chronic obstructive pulmonary disease (COPD), kyphoscoliosis, and obesity are reviewed, indicating a strong relationship between lung and chest wall behavior.

In both ARDS and COPD patients not only are the mechanics of the lung and the airways abnormal, but also the chest wall may as a result be altered. On the contrary, the chest wall abnormalities present in kyphoscoliosis and obesity reflect lung impairment.

In the present study, a model of chest wall mechanics in normal subjects is also presented. The application of this model, which is based on the measurement of pressure and volume displacements of the different compartments, to normal and pathologic subjects is now possible because of the availability of a new optoelectronic technique able to divide the partition chest wall into its different components, pulmonary rib cage, abdominal rib cage, and abdomen.

Key words Chest wall - normal subjects - critically ill patients 


\section{Introduction}

Respiratory mechanics, in critically ill patients, is usually considered as representative of the lung status and unaffected by the chest wall behaviour. Indeed, altered mechanical properties of the chest wall may limit ventilation, influence the work of breathing [1], affect the interaction between the respiratory muscles [2], hasten the development of respiratory failure and interfere with gas exchange [3].

Despite this central role of the chest wall in the respiratory function, the understanding of its behaviour has evolved slowly due to the difficulties in making direct measurements in humans. However, in these last years, several methods have been developed to evaluate chest wall mechanics, allowing to better define the role of the chest wall in different clinical situations. In this chapter we will discuss: 1) the "state of the art" of the methods available to evaluate the chest wall; 2) the mechanical behaviour of the chest wall during spontaneous breathing and during mechanical ventilation in normal subjects, in critically ill patients and in specific categories of patients (kyphoscoliotic and obese); 3) the main clinical consequences of these findings.

Chest wall mechanics: general concepts

The respiratory system is composed by the lung and the chest wall components, and the individual mechanical properties of each of them determine the behaviour of the respiratory system as a whole. We define the chest wall as those parts of the body that surround the lung and that move with ventilation, passive or active.

The airway pressure (Pao) required to inflate the respiratory system is the sum of the pressure required to inflate the lung (PL) plus the pressure required to inflate the chest wall $(\mathrm{Pw})$ :

$\mathrm{Pao}=\mathrm{PL}+\mathrm{Pw}$

Pao is easy to be directly obtained measuring the pressure at the airway opening from a side tap in the mouthpiece, face mask, or tracheal cannula.

$\mathrm{PW}_{\mathrm{W}}$ is more difficult to be measured, since it would require the direct [4] or the indirect measurement (i.e. esophageal pressure, Pes) [5] of the pressure in the pleural space.

The mechanics of the respiratory system considers the relationships between forces and the movements during breathing, i.e. the pressures and the volume displacements of its different components, basically lung and chest wall. The understanding of chest wall mechanics requires in particular the measurement of pressure and volume in its compartments: pleural and abdominal pressure ( $\mathrm{Ppl}$ and $\mathrm{Pab}$, respectively), rib cage and abdominal volume.
Pressure measurement

\section{Esophageal pressure}

The most widely used method for estimating $\mathrm{Ppl}$ is to record Pes by air-containing latex balloons which in turn transmit pressures to manometers [6]. Although the esophageal balloon technique is widely used in the measurements of lung and chest wall mechanics, its validity has been questioned by several authors due to the influence of the balloon volume, position and body posture on the measurement itself [7].

For accurate transmission of pressure, gas must be introduced into the balloon taking care to stay within the range of volume over which the rubber is unstretched. The best place to measure Pes seems to be the lower part of the esophagus. In this position, Pes accurately reflects changes in pleural pressure. Pes is relatively more positive in supine than in other postures. This is thought to result from the weight of structures anterior to the esophagus. However, it should be remembered that what it is important is not the absolute value of Pes but its modifications with gas movements into the respiratory system.

The most widely used method to validate the esophageal balloon technique as a measure of the pleural surface pressure consists of comparing esophageal and airway opening pressure during airways occlusion. A concordance between changes of esophageal pressure and changes of airway opening pressure is taken to indicate that the former provides a valid measure of changes in pleural surface pressure. To provide pressure variations during controlled mechanical ventilation compressions of the thorax are manually performed, while during assisted or spontaneous ventilation the inspiratory efforts of the patient are considered.

An alternative approach is the using of catheter mounted pressure transducers, which are usually better tolerated than balloon-catheter systems and give equivalent performances. A possible problem is the presence of uncontrollable shifts in the offset of the signal [8].

\section{Intra-abdominal pressure}

Two methods are currently available to estimate Pab: one is the direct measurement of gastric pressure (Pga) [9], while the other one is the measurement of the bladder pressure [10]. Pga is easily obtained using a gastric balloon similar to the esophageal one, positioned into the gastric cavity. Bladder pressure is measured by means of bladder catheters, after the infusion of $50-250 \mathrm{ml}$ of saline in the bladder. Bladder pressure is considered representative of the Pab and it is well correlated with Pga [11]. 
Fig. 1 Schematic diagram of the optoelectronic method for the analysis of the chest wall shape, volumes changes and movements

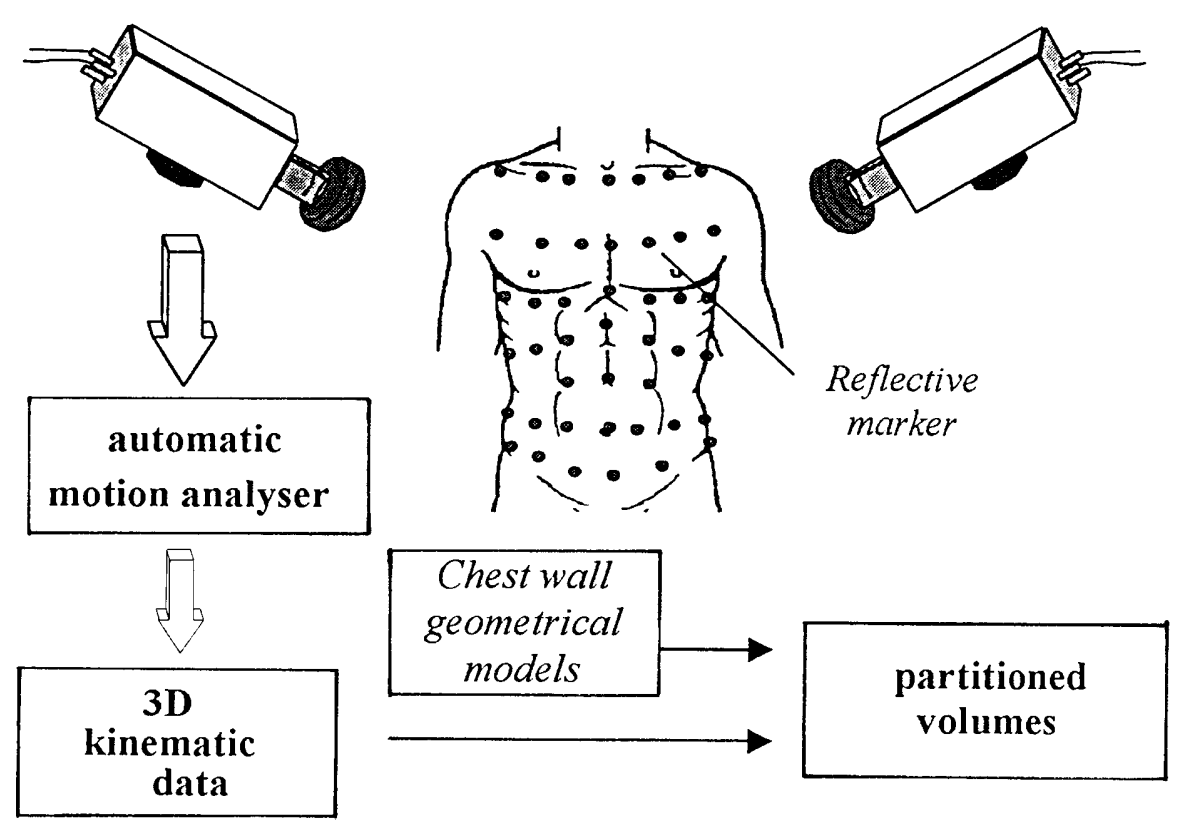

Volume measurement

Volume displacements of the entire chest wall are easily measured by plethysmography, but the separate volume displacements of its different components (rib cage, abdomen and diaphragm) are more difficult to assess. Therefore they are usually estimated indirectly from measurements of linear dimensions or areas. Techniques like Respiratory Inductive Plethysmography [12], magnetometry [13], linear differential transducers [14] are based on the assumptions that the respiratory system possesses two degrees of freedom, the displacements of the rib cage and abdomen, and that their volumes can be inferred by measurements of transversal sections or distances.

\section{Respiratory-Inductive Plethysmography (RIP)}

The RIP, originally described by Milledge et al. [12], has become the most widely accepted method of measuring ventilation noninvasively. The actual versions are generally constituted by two separate coils of Teflon-insulated wire sewn in a zigzag pattern onto elastic-fabricated bands measuring approximately $5-10 \mathrm{~cm}$ in height, normally placed just under the axillae and at the umbilical line. The self-inductance of the coil, and so the frequencies of the oscillator which is connected to it, is proportional to the cross-sectional area enclosed by the coil. The signal from the oscillator are sent to a demodulator unit which provides output voltage signals (AC or DC). The device measures the average of an infinite number of cross-sectional areas over its complete height rather than the circumference of the enclosed part. To obtain accurate results, an appropri- ate calibration for rib cage and abdomen cross-sectional area changes should be applied and, in the past, different methods have been developed [15]. Possible limitations of RIP calibration are the need of cooperative and trained subjects, difficulty in performing the particular respiratory manoeuvres (isovolume manoeuvres), the dependency on the body posture and lung volume.

Another important problem is that the chest wall moves with more than two degrees of freedom under a lot of circumstances [16] and even during breathing at rest [17]. Finally, these techniques ignore small but systematic distorsions of the rib cage [17].

\section{Imaging systems}

Three-dimensional X-ray computed tomography [18] and magnetic resonance imaging [19], although allowing accurate measurement of thoracoabdominal shapes and volumes, are affected by a low temporal resolution and, in the first case, ionizing and therefore invasive. In the past several three-dimensional optical techniques [21] have been proposed, but they were not developed in clinical practice because of their low temporal resolution and time-consuming data processing procedures. Besides, the boundaries between the different compartments are not easily defined and body landmarks must be manually identified.

\section{Optoelectronic method}

Recently, an optoelectronic system for kinematic analysis of the chest movements during respiration has been devel- 
oped [22]. It is based on an automatic motion analyzer that can give the three-dimensional location of many small reflective markers placed on the skin with the high temporal $(100 \mathrm{~Hz})$ and spatial accuracy $(0.2 \mathrm{~mm})$ required for respiratory measurements. This method has been applied with a configuration of marker points designed specifically to measure the volume of three chest wall compartments (the pulmonary and abdominal rib cage compartments and the abdomen) and of their vertical (right and left) variations. Figure 1 shows the anatomic placement of the anterior markers and the basic principle of measurement. The markers are tracked in three dimensions by four videocameras. Volumes for each compartment are calculated by constructing a triangulation over the surface and then using Gauss's theorem to convert the volume integral to an integral over this surface [23]. This method calculates absolute volumes and their changes during respiration. The validation of this technique has been presented for different body positions (erect, sitting, supine and prone [24]) and during different conditions (quiet and deep breathing, exercise [25], mechanical ventilation, phrenic stimulation [26], etc.). This new method presents several advantages that make it a potential tool useful for physiopathological studies and clinical applications. It was showed to be highly accurate and completely noninvasive. Besides, it does not require mouthpieces or other connections to the patient, it can be used during all the respiratory manoeuvres, without a subject specific calibration and without particular respiratory manoeuvres that require subject co-operation. Its main limitation, up to now, is the complexity in the analysis of the data which requires trained staff.

Static and dynamic properties of the chest wall

The statics of the chest wall considers the elastic properties ("static compliance") in equilibrium conditions, i.e. in absence of flow, at different lung volumes. It is assessed in relaxed situations, both induced by drugs (i.e. paralyzing agents) or intentionally (i.e. relaxation manoeuvres). The relationships between forces (pressures) and movements (volume derivatives) both in passive (i.e. during active inflation of gas into the airways) and active (i.e. during active breathing movements) conditions are instead described by dynamics. These relationships are usually reported in terms of viscoelastic properties (resistance, "dynamic compliance", and inertance). Different methods have been developed to evaluate the static and dynamic behaviour of the chest wall during passive and active breathing.

\section{Rapid airway occlusion method}

The rapid airway occlusion method is one of the most commonly used methods to evaluate static and dynamic characteristics of the chest wall both during passive and active

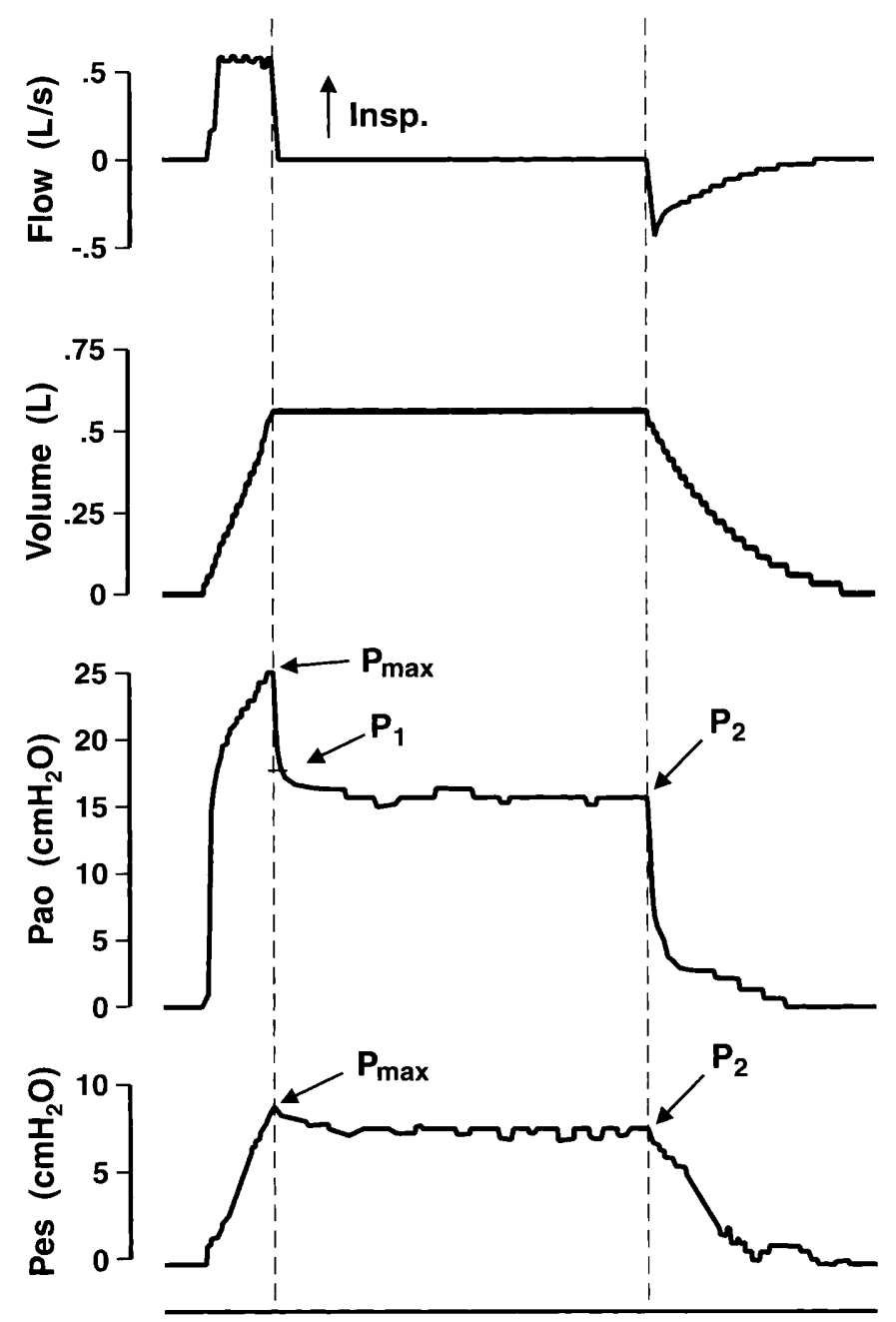

$1 \mathrm{~s}$

Fig. 2 Rapid airway occlusion method. Tracings (top to bottom) of flow, volume, airway pressure (Pao) and esophageal pressure (Pes). After an end-exspiratory occlusion, there is an immediate drop in Pao from a maximum pressure $\left(\mathrm{P}_{\max }\right)$ to a lower value $\left(\mathrm{P}_{1}\right)$, followed by a slow decay to a plateau $\left(\mathrm{P}_{2}\right)$ that represents the end-inspiratory recoil pressure of the respiratory system (Pst, rs). The end-inspiratory recoil pressure of the lung (Pst, L) is obtained as the difference betwen Pst, rs and Pst,w.

breathing [27]. Briefly, this method needs the recording of Pao and Pes, the flow and the inflated volume. It consists in a rapid occlusion of the airways at the end of an inspiration. As shown in Figure 2, immediately before occlusion, Pao reaches a value of $\mathrm{P}_{\max }$ which is governed by both elastic and non-elastic resistance. Immediately after airway occlusion, the airway pressure falls to $\mathrm{P}_{1}$, and $\mathrm{P}_{\max }-\mathrm{P}_{1}$ is believed to reflect airway resistance, as Raw $=$ $\left(\mathrm{P}_{\max }-\mathrm{P}_{1}\right)$ /flow rate of inflation. The decay of $\mathrm{P}_{1}$ to $\mathrm{P}_{2}$ represents the loss of the time-dependent element of tissue compliance (due to visco-elastic behaviour) and therefore 
represents the resistance offered by tissue (Rt) during inflation, $\mathrm{Rt}=\left(\mathrm{P}_{1}-\mathrm{P}_{2}\right) /$ flow rate of inflation. Note also that the static compliance equals the tidal volume divided by $\mathrm{P}_{2}$ and the dynamic compliance is equal to tidal volume divided by $\mathrm{P}_{1}$.

Results in anesthetized patients [28] indicate that Rt is not negligible and that the importance of this component has often been underestimated in the past. The occlusion manoeuver may be also performed during spontaneous breathing or during assisted ventilation [29].

\section{Forced oscillations technique}

Even though mechanical properties of the different respiratory components are frequently represented in terms of single resistances and compliances (viscoelastic modeling), this description is not complete. The forced oscillations technique [30] is an approach able to measure the mechanical impedance of the respiratory system and its frequency response. There are two common methods for applying forced oscillations to measure a mechanical impedance. With input impedance (Zin), forced pressure oscillations are imposed at the airway opening and it is measured the complex ratio between airways opening pressure $(\mathrm{Pao})$ and flow $(\mathrm{Zin}=\mathrm{Pao} / \mathrm{flow})$. With transfer impedance (Ztr), forced oscillations are imposed around the chest wall (Pcw) and the ratio Pcw/flow is measures [31]. Recent studies showed that transfer impedance is more representative of the airways and tissue mechanical properties than input impedance [32]. Unfortunately, up to now transfer impedance assessment requires the use of a plethysmograph to apply pressure signals to the chest wall and it does not allow to measure the characteristics of its different compartments. The above cited optoelectronic method could be applied also to overcome this problem, by determining transfer impedance in a reverse mode, i.e. imposing the forced oscillations at the airways and measuring transfer impedance as the ratio between airways opening pressure and the time derivative of the chest wall volume changes [33]. In general, the forced oscillations technique does not require patient co-operation and for this reason it is an attractive potential pulmonary function test, particularly for infants and ventilator dependent patients. The disadvantages are that the measurements are influenced by all respiratory structures, and their physiological and clinical interpretation are dependent on the used model and the considered frequency range.

\section{Normal subjects}

\section{Chest wall and respiratory muscles modeling}

In order to describe chest wall mechanics during spontaneous breathing in normal subjects, in the past several mod-

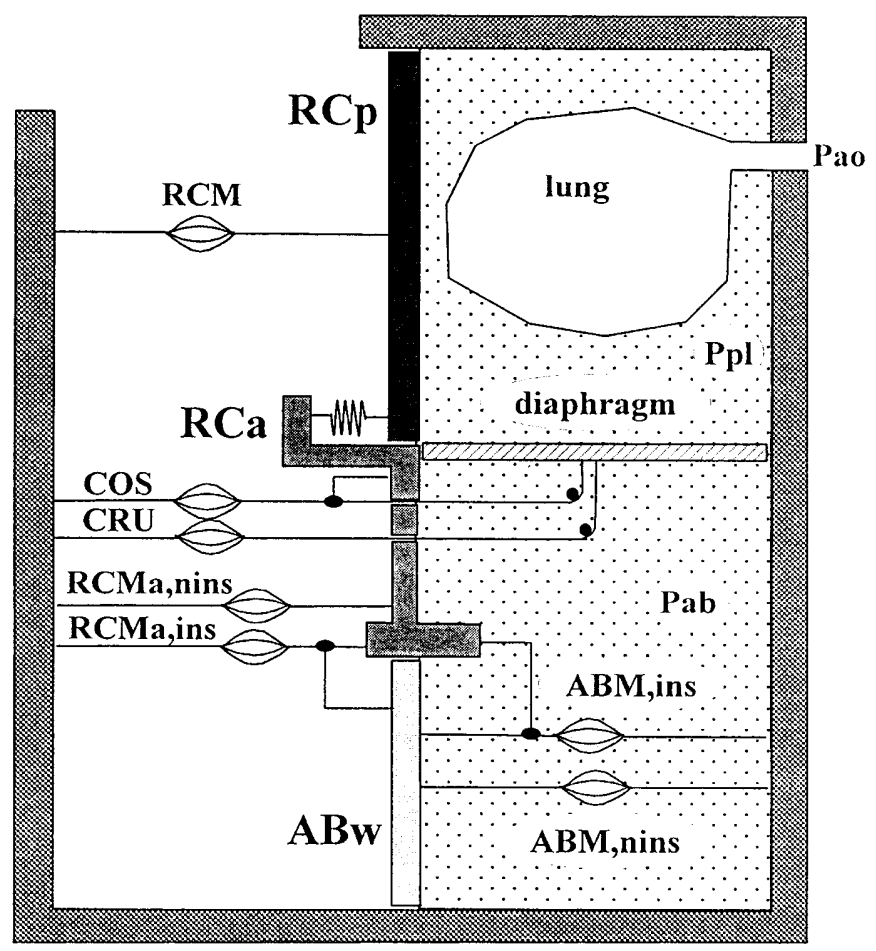

Fig. 3 Simplified mechanical model of the chest wall incorporating a two-compartment rib cage, i.e. pulmonary ( $\mathrm{RCp}$ ) and abdominal $(\mathrm{RCa})$ rib cage, and abdominal wall $(\mathrm{ABw})$. The respiratory muscles are grouped into: upper rib cage muscles (RCM); lower rib cage muscles (RCMa) divided into insertional (RCMa,ins) and non-insertional (RCMa,nins) on the abdomen; costal and crural diaphragm (COS and CRU, respectively); abdominal muscles (ABM) divided into insertional (ABM,ins) and non-insertional ( $\mathrm{ABM}, \mathrm{nins})$ on the lower rib cage. $\mathrm{Pao}, \mathrm{Ppl}$ and $\mathrm{Pab}$ represent the airways opening, pleural and intra-abdominal pressures, respectively

els have been proposed. The simplest model of chest wall motion was developed by Konno and Mead [14], who partitioned it into the rib cage and the abdomen. Successively, it was demonstrated that the rib cage can not be considered as a single compartment and therefore, different two-compartment rib cage models were proposed [17], in which the part apposed to the lung (pulmonary rib cage) was distinguished from the part apposed to the diaphragm (abdominal rib cage). In Figure 3, we reported a detailed mechanical model of respiratory muscle actions on the chest wall, divided into pulmonary rib cage, abdominal rib cage and abdominal wall. Upper rib cage muscles act on pulmonary rib cage and lower rib cage muscles act on abdominal rib cage. Lower rib cage muscles are divided into insertional and non-insertional on the abdominal wall. The diaphragm is splitted into its costal and crural parts. The abdominal muscles are divided into insertional and non-insertional on the rib cage. The spring represents the mechanical linkage between pulmonary rib cage and abdominal rib cage and describes the restoring force developed by distortions be- 
tween the two compartments away from the relaxation configuration [17].

In conclusion, the partitioning of the pressures differences across different parts of the chest wall and the possibility to measure the volume displacements of the twocompartment rib cage and abdomen have proved major advances in our knowledge of the act of breathing in normal conditions $[25,26]$. This is important to better understand the behaviour of the chest wall also in different "pathological" conditions.

\section{The chest wall during anesthesia and paralysis}

It has been well recognized that the induction of general anesthesia reduces oxygenation and functional residual capacity [34], while increases respiratory elastance and resistance $[35,36]$. These abnormalities are rapid, do not change with time and are unaffected by administration of a neuromuscular blockade. A loss of tonic activity in the chest wall muscles, both rib cage and diaphragm, is one of the possible factors explaining these physiologic changes induced by anesthesia. The primary source of the increased static respiratory system elastance appears to be the lung, since the static chest wall elastance appears to be little influenced over most of the range of lung volumes. Respiratory resistance increases after induction of anesthesia, but not significantly affecting chest wall resistance $[35,36]$. Data relative to changes in chest wall shape with the induction of anesthesia are scanty and obtained in very small samples of subjects. Anesthesia and paralysis, in fact, decrease the external antero-posterior diameter and increase the lateral diameter of the thorax and abdomen. Froese and Bryan [37] examined the diaphragmatic shape and found that the induction of anesthesia caused a cephalad shift of the end-expiratory position of the dependent part of the diaphragm, with no further modification after paralysis. Shifts in the non dependent part were inconsistent. In contrast, Krayer et al. [38] found no consistent net chephalad shift in end-expiratory diaphragmatic position with induction of anesthesia, concluding that the contribution of the diaphragm to the reduction in lung volume caused by anesthesia may be generally smaller than originally thought. Moreover, they found that an inward displacement of the rib cage accounts for most of the decrease in lung volume. Another interesting aspect is related to the pattern of the diaphragmatic movement during mechanical ventilation. Several authors [37, 38] found, in supine position, a prevalent motion of the non dependent regions of the diaphragm and a more uniform motion during large tidal volumes Finally, during anesthesia the relative movement of the rib cage and the abdomen is reversed. While during spontaneous breathing the prevalent movement is in the abdominal part, during anesthesia and paralysis is prevalent in the rib cage. The anteroposterior diameters of both the rib cage and abdo- men increase during a tidal breath, while the lateral diameters decrease [39].

In conclusion, it seems that: 1) anesthesia changes the shape and pattern of motion of the chest wall, but not its elastic and resistive properties; 2 ) the reduction in lung volume seems related to more important changes in the rib cage than in the diaphragm; 3) distribution of inspired gases during mechanical ventilation is prevalent in the rib cage and the movement of the diaphragm is prevalent in the non dependent lung regions; 4) the added paralysis has no effect. All these changes in chest wall mechanics may be implicated in the abnormalities in the respiratory function after induction on anesthesia.

\section{Acute Respiratory Distress Syndrome Patients}

\section{Chest wall behaviour in supine position}

The mechanical properties of the respiratory system are severely affected in Adult Respiratory Distress Syndrome (ARDS) and are supposed to mainly reflect alterations in lung rather then chest wall mechanics. However, only few studies reported chest wall mechanical data in patients with ARDS, during sedation and paralysis [40, 41, 42, 43]. On average the mean value of the chest wall elastance was $10.2 \pm 2.5 \mathrm{~cm} \mathrm{H}_{2} \mathrm{O} / \mathrm{L}$, markedly lower than that reported in normal subjects [27]. However, all these studies had some limitations since they were performed in a limited number of inhomogenous patients, often not including a control group, and using different methods of measurements. More recently, we reported [44], in a selected group of patients with different degree of acute lung injury, a substantial increase in chest wall elastance (i.e., decrease in compliance) compared to normal subjects. The increase in elastance of the chest wall was attributed to different factors: 1) a decrease in lung volume, which could produce a decrease in the volume of the rib cage-abdominal compartment, moving it to a less compliant portion of its pressure-volume curve; 2) true alterations of the chest wall due to abdominal distension, edema, pleural effusion and so forth. The first hypothesis was ruled out since a direct relationship between lung and thoracic volume does not apply to ARDS since a significant portion of the thoracic volume is occupied by blood, exudate, edema and pleural fluid [45]. Consequently, these results were ascribed to alterations of the intrinsic properties of the chest wall. Although in that study the authors were unable to identify the specific factors affecting chest wall elastance, some hypothesis were proposed. Common causes of increased chest wall elastance are due to the rib cage (age, anatomic deformities, edema, obesity), the abdomen (obesity, ascites, abdominal distention) and the pleural space (pleural effusion, pneumothorax, haemothorax, empyema). Among them the most attractive one was an increase in the intra-abdominal pressure. It is well known that both in animals [46] and in nor- 
mal [47] subjects the increase in intra-abdominal pressure may significantly affect the chest wall mechanics. Both surgical procedures on the abdomen, the continuous use of sedatives and the overfluidic treatment, commonly used in these patients, may impair abdominal function producing a possible increase of the intra-abdominal pressure [48].

Moreover, the mechanical properties of the chest wall may be influenced by the etiology leading to ARDS. We studied two groups of patients with ARDS: one group had ARDS due to a "direct" insult to the lung (i.e. bacterial, viral or fungal pneumonia, etc.), the other group had ARDS due to an "indirect" insult to the lung (i.e. surgical abdominal problems) [49]. We found that the first group was characterized by severe alterations in the lung mechanics with the chest wall substantially unaffected, while the second one was characterized by severe alterations in the chest wall with minimal alterations in the lung. Interestingly, the increase in chest wall elastance was paralleled by an increase in the intra-abdominal pressure (Figure 4). It was thus evident that the alteration of the chest wall is not an hallmark of all kinds of ARDS, but specific of "indirect" lung injury, at least in the first days of the disease. However, it is possible that also other factors, such as the duration of mechanical ventilation, sedation, nutrition may lead to an increase in the intra-abdominal pressure, and thus to abnormalities in chest wall mechanics. In line with these observations Ranieri et al. [50] compared patients with ARDS consequent to major abdominal surgery ("surgical ARDS") to patients with "medical ARDS". In surgical ARDS the static inspiratory P-V relationship of the respiratory system and lung showed a downword concavity indicating that compliance decreased with tidal volume, and suggesting alveolar overdistensions. Patients with ARDS consequent to medical conditions had an upward concavity, indicating an increasing compliance and alveolar recruitment during inflation. Finally, Mergoni et al. [51] showed in a subset of patients with ARDS that the lower inflection point of the static P-V curve of the respiratory system was due to the shape of the P-V curve of the chest wall and of the lung.

In conclusion, contrary to a common notion, the mechanics of the chest wall may be altered in patients with ARDS and influence the respiratory function during mechanical ventilation.

\section{Chest wall behaviour in prone position}

A limited number of studies investigated the behaviour of the chest wall in prone position both during spontaneous breathing and mechanical ventilation. Prone position is usually adopted in ARDS patients to improve oxygenation, modifying the regional distribution of regional lung inflation and ventilation while likely unaffecting regional perfusion $[52,53]$. There is evidence that the characteristics of the chest wall may influence the modifications in re-

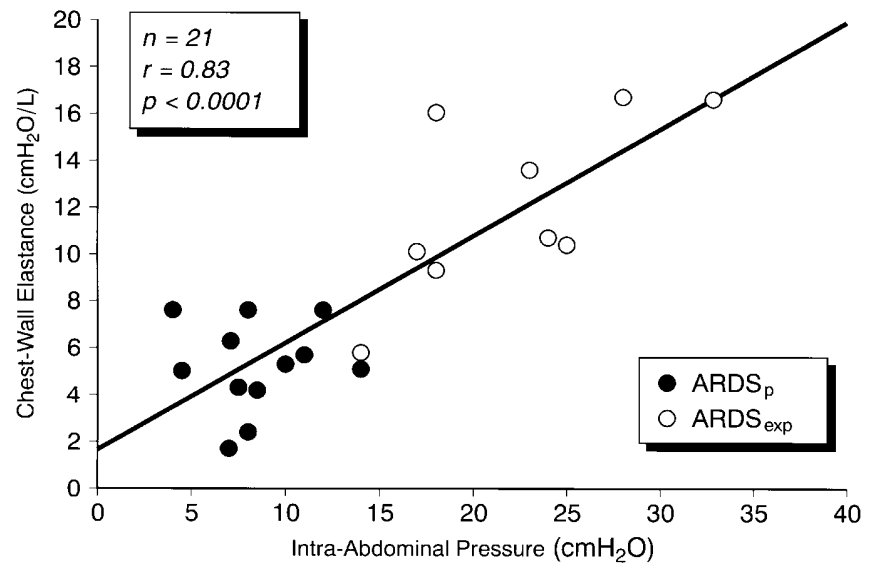

Fig. 4 Relationship between chest wall elastance and intra-abdominal pressure. Open circles represent patients with extra-pulmonary

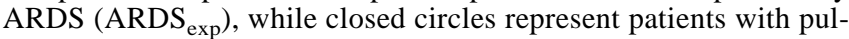
monary ARDS (ARDS ${ }_{\mathrm{p}}$ ). Modified from ref 49

gional inflation and ventilation prone position [54]. Both in normal [55] and obese [56] subjects during sedation and paralysis we found that the improve in oxygenation in prone position was mainly related to changes in chest wall mechanics (i.e. chest wall compliance) more than in endexpiratory lung volume increase. More recently, we reported in 16 ARDS patients with primary ARDS a strict correlation between changes in chest wall mechanics in prone position and oxygenation improvement [57]. In particular we found that patients who more reduced chest wall compliance while prone more improved oxygenation. Since patients with better chest wall compliance were those who more reduced chest wall compliance while prone, it was evident that chest wall compliance in supine could predict in this series of patients the response of oxygenation while prone. We hypothesized that we may have two groups of patients: 1) patients with soft ventral (i.e. near to the sternum) chest wall compliance whose ventilation is less distributed to the diaphragm-abdomen (where are present the majority of atelectasis). When these patients are turned prone, the ventral chest wall movement is reduced since it is lying on the stiff surface of the bed. Thus ventilation is more directed towards the diaphragm-abdomen, improving oxygenation; 2) patients with stiff ventral chest wall compliance, in which prone position does not modify the distribution of ventilation towards the diaphragm-abdomen, thus not improving oxygenation. From these findings it is evident that externally modifying the regional mechanical characteristics of the chest wall, it is possible to improve ventilation distribution towards the diaphragm-abdominal compartment, thus improving oxygenation while supine. Two recent studies investigated this possibility applying an external weight on the ventral part of the chest wall while patient supine, likely causing a redistribution in ventilation $[58,59]$. They found a significant improve- 
ment in oxygenation related to the changes in chest wall compliance and abdominal-diaphragmatic ventilation (as expected, patients who more reduced chest wall compliance with external weight more improved oxygenation). Moreover, they found that the improvement in oxygenation was paralleled by a reduction in end-expiratory lung volume with an improvement in lung compliance, i.e. the patients were likely ventilated to a less overdistended part of the lung P-V curve.

In conclusion, external regional modification of the chest wall mechanics seems to be an easy, noninvasive attractive tool to improve oxygenation and to perform a less traumatic ventilation in ARDS patients.

\section{Chronic Obstructive Pulmonary Disease Patients}

Chronic obstructive disease (COPD) with acute exacerbation of acute respiratory failure (ARF) is characterized by an increase in airway resistance and a loss of lung elastic recoil with normal contribution of the chest wall [60]. As a result, airflow limitation develops, leading to the presence of dynamic hyperinflation and intrinsic positive endexpiratory pressure (PEEPi) [61]. These alterations lead to an increased work of breathing, but the role of the chest wall is usually considered negligible [62]. However, recent data suggest that the chest wall contribution to the elastic properties of the respiratory system may be substantial [63, 64]. We systematically investigated the chest wall mechanics in a group of mechanically ventilated COPD patients with ARF compared to normal subjects of similar age [65]. We found an increased chest wall elastance compared to normal subjects, despite a substantially normal lung elastance. The chest wall resistance was also increased compared to normal. As for ARDS patients, we may hypothesize that several factors contributed to our finding. Altered intestinal motility, eventually leading to colonic pseudoobstruction, has been shown to occur with un unexpectedly high frequency in mechanically ventilated COPD patients with ARF [66]. Narcotic sedation, which is frequently used in critically ill patients may further aggravate this condition. The resulting abdominal distension might increase the intra-abdominal pressure and thus the chest wall elastance.

In conclusion, COPD patients with ARF are characterized not only by an abnormal increase in airway resistance but also be severe alterations in the mechanical properties of the chest wall, elastance and resistance.

\section{Kyphoscoliotic patients}

Kyphoscoliosis is a deformation of the spine involving both lateral (scoliosis) and antero-posterior (kyphosis) displacement. The most common form of kyphoscoliosis is idiopathic, although secondary kyphoscoliosis may be ob- served as a consequence of various neuromuscular diseases. Severe alterations of the intrinsic characteristic of the chest wall are often referred to the intensive care unit for noninvasive or conventional ventilatory support. These patients are characterized: 1) by a severe reduction in respiratory system compliance with an equally distributed compliance in the lung and chest wall;2) an increase in airway resistance, likely due to a reduction in end-expiratory lung volume [67]. Moreover, other authors have shown that these patients may present an impaired inspiratory muscle function which contributes with thoracic rigidity to the progression of respiratory failure [68].

In conclusion kyphoscoliotic patients are characterized by severe respiratory mechanical impairment, which is not only due to the chest wall component, as expected, but also to the lung component.

\section{Obese patients}

Obese patients are defined by the presence of a body mass index higher than $40 \mathrm{~kg} / \mathrm{m}^{2}$ and characterized by severe impairment in respiratory mechanics, lung volumes and gas-exchange, particularly during sedation, paralysis and mechanical ventilation. Moreover, they are at high risk of postoperative respiratory complications [69]. Recently, we found that not only the lung mechanics but also chest wall mechanics is severely impaired in obese patients, both in the pre-operative and postoperative period [70, 71, 72]. They are characterized by a relatively low lung compliance and high airway resistance due to the severe reduction in end-expiratory lung volume, and by a marked reduction in chest wall compliance, mainly related to the increased intra-abdominal pressure. We also found that application of PEEP or recruitment manoeuvres in the immediate postoperative period may help in improving respiratory function in obese patients and likely reduce postoperative complications [73].

In conclusion, severe alterations in the mechanical behaviour of both the lung and chest wall may be the main cause of the high frequency of postoperative respiratory complications in this kind of patients.

\section{Physiopathological and clinical implications}

These findings indicate that the evaluation of the chest wall behaviour is not only important from a speculative point of view, but also from a clinical one.

They may have "important" physiopathological and clinical consequences on:

\section{1) Interpretation of respiratory mechanics}

Now we have evidence that the chest wall mechanics may be abnormal in critically ill patients. Consequently, the data relative to the total respiratory system mechanics may not 
be considered always representative of the lung alone. For example, two patients may have the same respiratory system elastance but, if the chest wall contribution is different, lung elastance will be different. Thus, if a physician measure the respiratory system elastance along to have an idea of the lung elastance he may be misled.

\section{2) Etiology of ARDS}

The measurement of chest wall mechanics may play a relevant role in the recognition of the two forms of ARDS, "direct" and "indirect", likely leading to an improvement in clinical management. Two major complications of positive pressure ventilation in patients with ARDS are barotrauma and hemodynamic impairment, both related to the elevated elastance of the respiratory system. High lung elastance and low chest wall elastance in "direct" ARDS, in fact, result in elevated transmural pressure, a risk factor for barotrauma, and low pleural pressure, whereas lower lung elastance and higher chest wall elastance in "indirect" ARDS result in elevated pleural pressure, with consecutive possible impairment of venous return, cardiac filling, and cardiac output.

\section{3) Oxigenation improvement in prone position}

Partitioning of total respiratory system mechanics into its lung and chest wall components may be extremely useful to predict possible positive response in oxygenation when patients with ARDS are in prone position. Lower chest wall elastance in supine position higher is the improvement in oxygenation while prone, likely due to modifications in regional chest wall mechanics.

\section{4) Current recommendations on the ventilatory treatment}

The recommendations of the consensus group regarding high airway pressure during the ventilatory management of ARDS emphasized that a plateau pressure of the respiratory system higher or equal to $35 \mathrm{~cm} \mathrm{H}_{2} \mathrm{O}$ is of concern and that reductions in tidal volume may be necessary [74]. They went on to point out that if a clinical situation is associated with decreased chest wall compliance then the plateau pressure higher than $35 \mathrm{~cm} \mathrm{H}_{2} \mathrm{O}$ may be acceptable. This is something that the more recent trials have not addressed. Lung distension is directly related to transpulmonary pressure. Normal lung will reach its maximum distension when a transpulmonary pressure reaches $30-35 \mathrm{~cm}$ $\mathrm{H}_{2} \mathrm{O}$. Lung overdistension can usually be avoided by preventing transpulmonary pressure from exceeding $30-35 \mathrm{~cm}$ $\mathrm{H}_{2} \mathrm{O}$. A treatment strategy which uses plateau pressure of the respiratory system as a surrogate for transpulmonary pressure may overestimate the true transpulmonary pressure.

\section{5) Interpretation of hemodynamics}

The different mechanical characteristics of the chest wall (in ARDS patients implies that) influence the transmission in the pleural space of the airway pressure is different. In fact, for the same airway pressure, patients with lower chest wall elastance will have less increase in pleural pressure. On the contrary, patients, with higher chest wall elastance will have much more increase in pleural pressure. This means that the (compromise of) the venous return to the heart is less affected, for the same airway pressure, in a patient with low chest wall elastance compared to a patient with a high chest wall elastance. Evident consequences are also related to the interpretation of the intravascular pressures, central venous pressure and wedge pressures and the effects of application of different airway pressures on hemodynamics.

\section{6) Evaluation of the work of breathing}

The work of breathing is frequently measured both for research and clinical purposes. However, what is generally called "work of breathing" is really the work of breathing done by the respiratory muscles on the lung alone. But the patient's work of breathing results from the action of the respiratory muscles to inflate not only the lung but also to expand the chest wall (rib cage, diaphragm and abdomen). Thus in presence of alterations of the chest wall, the measurement of the "work of breathing" on the lung may markedly underestimate the total respiratory "work of breathing". This should be kept in mind in the evaluation and interpretation of this kind of measurement.

\section{Conclusions}

The role of the chest wall on respiratory function during passive and active ventilation has not been widely investigated due to the difficulties to measure the chest wall behavior, both as a whole and divided into its components, separately from the total respiratory system. Nevertheless, the chest wall appears to influence in a substantial way the mechanics of breathing, distribution of ventilation and gasexchange with several important clinical implications in critically ill patients.

Acknowledgements The authors wish to thank Prof. L. Gattinoni and Prof. A Pedotti for their thoughtful contributions. 


\section{References}

1. Agostoni E (1964) Action of respiratory muscle. In: Fenn WO and Rahn $\mathrm{H}$ (eds) Handbook of Physiology, 2nd edn. American Physiological Society, Washington DC, pp 377-386

2. Zocchi L, Garzaniki N, Newman S, Macklem PT (1987) Effect of hyperventilation and equalization of abdominal pressure on diaphragmatic action. J Appl Physiol 62: 1655-1664

3. Liu S, Margulies SS, Wilson TA (1990) Deformation of the dog lung in the chest wall. J Appl Physiol 68: 1979-1987

4. Lai-Fook SJ, Rodarte JR (1991) Pleural pressure distribution and its relationship to lung volume and interstitial pressure. J Appl Physiol 70:967-978

5. Milic-Emili J, Mead J, Turner JM (1964) Improved technique for estimating pressure from esophageal balloons. J Appl Physiol 19:207-211

6. Maxted KJ, Shaw A, Macdonald TH (1977) Choosing a catheter system for measuring intra-oesophageal pressure. Med Biol Eng Comput 15:398-401

7. Knowles JH, Hong SK, Rhan H (1959) Possible errors using esophageal balloon in determination of pressure-volume characteristics of the lung and thoracic cage. J Appl Physiol 14:525-530

8. Peters RJA, Meijer JH, Kingma R, Scheffer GJ, Heethaar RM (1998) Evaluation of catheter-mounted transducers for intra-oesophageal pressure recording in respiratory functions tests. Med Biol Eng Comput 36:562-567

9. Agostoni E, Rhan H (1960) Abdominal and thoracic pressures at different lung volumes. J Appl Physiol 15:10871092

10. Iberti TJ, Kelly KM, Gentili DR, Hirsch S (1987) A simple technique to accurately determine intra-abdominal pressure. Crit Care Med 15:1140-1142

11. Collee GG, Lomax DM, Ferguson C, Hanson GC (1993) Bedside measurement of intraabdominal pressure (IAP) via an indwelling nasogastric tube: clinical validation of the technique. Intensive Care Med 19:478-480

12. Milledge JS, Stott FD (1977) Inductive plethysmography - a new respiratory transducer. J Physiol (Lond) 267:4

13. Mead J, Peterson N, Grimby G, Mead J (1967) Pulmonary ventilation measured from body surface movements. Science 156: 1383-1384

14. Konno K, Mead J (1967) Measurement of the separate volume changes of rib cage and abdomen during breathing. J Appl Physiol 22:407-422
15. Stadling JR, Chadwick GA, Quirk C, Phillips T (1985) Respiratory inductance pletismography: calibration techniques, their validation and the effects of posture. Bull Eur Physiopathol Respir 21:317-324

16. Smith JC, Mead J (1968) Three degree of freedom description of movement of the human chest wall. J Appl Physiol 60: 928-934

17. Ward ME, Ward JW, Macklem PT (1992) Analysis of chest wall motion using a two-compartment rib cage model. J Appl Physiol 72: 1338-1347

18. Krayer S, Rehder K, Beck KC, Cameron PD, Didier EP, Hoffman EA (1987) Quantification of thoracic volumes by three-dimensional imaging. J Appl Physiol 62:591-598

19. Gauthier AP, Verbanck S, Estenne M, Segebarth C, Macklem PT, Paiva M (1994) Three-dimensional reconstruction of the in vivo human diaphragm shape at different lung volumes. J Appl Physiol 76:495-506

20. Peacock A, Gourlay A, Denison D (1985) Optical measurement of the change in trunk volume with breathing. Bull Eur Physiopath Resp 21:125-129

21. Kovats F (1970) Plethysmographie optique du tronc. Bull Eur Physiopath Resp 6:833-845

22. Ferrigno G, Carnevali P, Aliverti A, Molteni F, Beulke G, Pedotti A (1994) Three-dimensional Optical Analysis of Chest Wall Motion. J Appl Physiol 77 (3): 1224-1231

23. Cala SJ, Kenyon CM, Ferrigno G, Carnevali P, Aliverti A, Pedotti A, Macklem PT, Rochester DF (1996) Chest wall and lung volume estimation by optical reflectance motion analysis. J Appl Physiol 81:2680-2689

24. Dellacà R, Aliverti $A$, Pelosi $P$, Gattinoni L, Pedotti A (1998) Optical analysis of chest wall volume in supine and prone position. Eur Respir J 12, 28:399S

25. Aliverti A, Cala SJ, Duranti R, Ferrigno G, Kenyon CM, Pedotti A, Scano G, Sliwinski P, Macklem PT, Yan S (1997) Human Respiratory Muscle Actions and Control during Exercise. J Appl Physiol 83: 1256-1269

26. Kenyon CM, Cala SJ, Yan S, Aliverti A, Scano G, Duranti R, Pedotti A, Maklem PT (1997) Rib Cage Mechanics during Quiet Breathing and Exercise in Humans. J Appl Physiol 83: $1242-1255$

27. D'Angelo E, Robatto FM, Calderini E, Tavola M, Bono D, Milic-Emili J (1991) Pulmonary and chest wall mechanics in anesthetized and paralyzed humans. J Appl Physiol 70: 2602-2610
28. D'Angelo E, Prandi E, Tavola M, Calderini E, Milic-Emili J (1994) Chest wall interrupter resistance in anethetized paralyzed humans. J Appl Physiol 77: 883-887

29. Pesenti A, Pelosi P, Foti G, D'Andera L, Rossi N (1992) An interrupter technique for measuring respiratory mechanics and the pressure generated by respiratory muscles during partial ventilatory support. Chest 102:918-923

30. DuBois AB, Brody AW, Lewis DH, Burgess BF (1956) Oscillation mechanics of lung and chest in man. J Appl Physiol 8:587-594

31. Michaelson ED, Grassman ED, Peters WR (1975) Pulmonary mechanics by spectral analysis of forced random noise. J Clinic Invest 56:1210-1230

32. Lutchen KR, Everett JR, Jackson AC (1993) Influence of frequency range and input impedance on interpreting the airways tissue separation implied from transfer impedance. J Appl Physiol 73: 1089-1099

33. Aliverti A, Dellacà R, Ferrigno G, Pelosi P, Pedotti A (1997) Chest wall mechanics using the forced oscillation technique and optoelectronic methods. Eur Respir J 10:23S

34. Tokics L, Hedenstierna G, Strandberg A, Brismar B, Lunquist H, Hedenstierna G (1987) Lung collapse and gas exchange during general anesthesia: effects of spontaneous breathing, muscle paralysis, and positive ene-expiratory pressure. Anesthesiology 66: 157- 167

35. Rehder K, Mallow JE, Fibuch EE, Krabill DR, Sessler AD (1974) Effects of isoflurane anesthesia and muscle paralysis on respiratory mechanics in normal man. Anesthesiology 41:477-485

36. Westbrook PR, Stubbs SE, Sessler AD, Rheder K, Hyatt RE (1973) Effects of anesthesia and muscle paralysis on respiratory mechanics in normal man. J Appl Physiol 44: 114-123

37. Froese AB, Bryan AC (1974) Effects of anesthesia and paralysis on diaphragmatic mechanics in man. Anesthesiology 41:242-255

38. Krayer S, Rehder K, Vettermann J, Didier EP, Ritman EL (1989) Position and motion of the human diaphragm during anesthesia and paralysis. Anesthesiology 70: 891-898

39. Hedenstierna G, Lofstrom B, Lundh R (1981) Thoracic gas volume and chestabdomen dimensions during anesthesia and muscle paralysis. Anesthesiology 55:499-506 
40. Suter PM, Fairley HB, Isenberg MD (1978) Effect of tidal volume and positive end-expiratory pressure on compliance during mechanical ventilation. Chest 73: 158-162

41. Katz JA, Zinn SE, Ozanne GM, Fairley HB (1982) Pulmonary, chest wall and lung-thorax elastances in acute respiratory failure. Chest 80:304-311

42. Jardin F, Genevray B, Brun-ney D, Bourdarias JP (1985) Influence of lung and chest wall compliances on transmission of airway pressure to the pleural space in critically ill patients. Chest 88: 653-658

43. Polese G, Rossi A, Appendini L, Brandi G, Bates JHT, Brandolese R (1991) Partitioning of respiratory mechanics in mechanically ventilated patients. J Appl Physiol 71:2425-2433

44. Pelosi P, Cereda M, Foti G, Giacomini M, Pesenti A (1995) Alterations in lung and chest wall mechanics in patients with acute lung injury: effects of positive end-expiratory pressure. Am J Respir Crit Care Med 152:531-537

45. Pelosi P, D'Andrea L, Vitale G, Pesenti A, Gattinoni L (1994) Vertical gradient of regional lung inflation in adult respiratory distress syndrome. Am J Respir Crit Care Med 149: 8-13

46. Mutoh T, Lamm WJE, Hildebrandt J, Albert RK (1991) Abdominal distension alters regional pleural pressures and chest wall mechanics in pigs in vivo. J Appl Physiol 70:2611-2618

47. Pelosi P, Foti G, Cereda M, Vicardi P, Gattinoni L (1996) Effects of carbon dioxide insufflation for laparoscopic cholecystectomy on the respiratory system. Anaesthesia 51:744-749

48. Schein M, Rucinski J, Wise L (1996) The abdominal compartment syndrome in the critically ill patients. Curr Opinion in Critical Care 2:287-294

49. Gattinoni L, Pelosi P, Suter PM, Pedoto A, Vercesi P, Lissoni A (1998) Acute respiratory distress syndrome caused by pulmonary and extrapulmonary ARDS. Different syndromes? Am J Respir Crit Care Med 157:387-393

50. Ranieri VM, Brienza N, Santostasi S, Puntillo F, Mascia L, Vitale N, Giuliani R, Memeo V, Bruno F, Fiore T, Brienza A, Slutsky SA (1997) Impairment of lung and chest wall mechanics in patients with acute respiratory distress syndrome. Role of abdominal distension. Am J Respir Crit Care Med 156: 1082-1091

51. Mergoni M, Martelli A, Volpi A, Primavera S, Zuccoli P, Rossi A (1997) Impact of positive end-expiratory pressure on chest wall and lung pressurevolume curve in acute respiratory failure. Am J Respir Crit Care Med 156:846-854
52. Chatte' G, Sab JM, Dubois JM, Sirodot M, Gaussorgues P, Robert D (1997) prone position in mechanically ventilated patients with severe acute respiratory failure. Am J Respir Crit Care Med 155:473-478

53. Lamm WJE, Graham MM, Albert RK (1994) Mechanism by which the prone position improves oxygenation in acute lung injury. Am J Respir Crit Care Med 150: 184-193

54. Dellaca' R, Aliverti A, Pelosi P, Gattinoni L, Pedotti A (1998) Optical analysis of chest wall volume in supine and prone position. Eur Respir J 24:P2623

55. Pelosi P, Croci M, Calappi E, Cerisara M, Mulazzi D, Vicardi P, Gattinoni L (1995) The prone position during general anesthesia minimally affects respiratory mechanics while improving functional residual capacity and increasing oxygen tension. Anesth Analg 152:531-537

56. Pelosi P, Croci M, Cerisara M, Vicardi P, Lissoni A, Gattinoni L (1996) Prone position during general anesthesia improves pulmonary function in obese patients. Anesth Analg 83:578-583

57. Pelosi P, Tubiolo D, Mascheroni D, Vicardi P, Crotti S, Valenza F, Gattinoni L (1998) The effects of prone position on respiratory mechanics and gas exchange during acute lung injury. Am J Respir Crit Care Med 157:387-393

58. Lagonidis D, Vakalos A, Matamis D, Riggos D (1998) Improvement in gasexchange by reducing the chest wall compliance. Intensive Care Med 24: S386

59. Panigada M, Riva E, Carrieri F, Bottino N, Allegritti E, Resta M, Pelosi P, Gattinoni L (1998) Effects of artificial changes of chest wall compliance on respiratory mechanics and gas-exchange in patients with acute respiratory failure. Proceedings SMART, Springer-Verlag (Milano), 63

60. Guerin C, Coussa ML, Eissa NT (1993) Lung and chest wall mechanics in mechanically ventilated COPD patients. J Appl Physiol 74: 1570-1580

61. Pepe PE, Marini JJ (1982) Occult positive end-expiratory pressure in mechanically ventilated patients with airflow obstruction: the auto-PEEP effect. Am Rev Respir Dis 126: 166-170

62. Coussa ML, Guerin C,Eissa NT (1993) Partitioning of work of breathing in mechanically ventilated COPD patients. J Appl Physiol 75:1711-1719

63. Ranieri VM, Giuliani R, Mascia L, Grasso S, Petruzzelli V, Bruno F, Fiore T, Brienza A (1996) Chest wall and lung contribution to the elastic properties of the respiratory system in patients with chronic obstructive pulmonary disease. Eur Respir J 9: 12321239
64. Ranieri VM, Giuliani R, Cinnella G, Mascia L, Bruno F, Fioer T, Brienza A (1993) Physiologic effects of positive end-expiratory pressure in patients with chronic obstructive pulmonary disease during acute ventilatory failure and controlled mechanical ventilation. Am Rev Respir Dis 147:5-13

65. Musch G, Foti G, Cereda M, Pelosi P, Poppi D, Pesenti A (1988) Lung and chest wall mechanics in normal anesthetized subjects and in patients with COPD at different PEEP levels. Eur Respir J 10:2545-2552

66. Bonmarchand G, Denis P, Weber J, Lerebours-Pigonierre G, Massari P, Leroy J (1989) Motor abnormalities of digestive and urinary tracts in patients on ventilator for acute exacerbation of chronic obstructive pulmonary disease. Digestive Diseases and Sciences 34: 1231-1237

67. Conti G, Rocco M, Antonelli M, Bufi M, Tarquini S, Lappa A, Gasparetto A (1997) Respiratory system mechanics in the early phase of acute respiratory failure due to severe kyphoscoliosis. Intensive Care Med 23:539-544

68. Lisboa C, Moreno R, Fava M, Ferretti R, Cruz E (1985) Inspiratory muscle function in patients with severe kyphoscoliosis. Am Rev Respir Dis 132: 48-52

69. Shenkman Z, Shir Y, Brodsky JB (1993) Perioperative management of the obese patient. Br J Anaesth 70:349-359

70. Pelosi P, Croci M, Ravagnan I, Vicardi P, Gattinoni L (1996) Total respiratory system, lung and chest wall mechanics in sedated paralyzed postoperative morbidly obese patients. Chest 109 : 144-151

71. Pelosi P, Croci M, Ravagnan I, Cerisara M, Vicardi P, Lissoni A, Gattinoni L (1997) Respiratory system mechanics in sedated paralyzed morbidly obese patients. J Appl Physiol 82:811-818

72. Pelosi P, Croci M, Ravagnan I, Tredici S, Pedoto A, Lissoni A, Gattinoni L (1998) The effects of body mass on lung volumes, respiratory mechanics and gas-exchange during general anesthesia. Anesth Analg 87:654-680

73. Pelosi P, Norsa A, Croci M, Vicardi P, Pedoto A, Gattinoni L (1995) Physiologic effects of positive end-expiratory pressure (PEEP) in postoperative sedated-paralyzed morbidly obese patients. Intensive Care Med 21:S58

74. Slutsky AS (1993) Mechanical ventilation. Chest 104: 1833-1859. Also, (1994) Intensive Care Med 20:64-79 